NDP -027

\title{
GEOSECS ATLANIIC, PACIFIC, INDIAN, and MEDITERRANEAN RADIOCARBON DATA
}

\author{
Contributed by \\ H. Göte Östlund \\ Tritium Laboratory \\ Rosenstiel School of Marine and Atmospheric Sciences \\ University of Miami \\ Miami, Florida \\ Minze Stuiver \\ Quaternary Isotope Laboratory \\ University of Washington \\ Seattle, Washington \\ January, 1988

\begin{abstract}
Prepared by
T.A. Boden

Environmental Sciences Division

Oak Ridge National Laboratory

Oak Ridge, Tennessee 37831-6050

operated by

Martin Marietta Energy Systems, Inc. for the

U.S. DEPARTMENT OF ENERGY

under Contract NO. DE-AC05-840R21400
\end{abstract}

